\title{
A tiered approach to investigate the mechanism of anti-inflammatory activity of an herbal medicinal product containing a fixed combination of thyme herb and primula root extracts
}

\author{
Jan Seibel ${ }^{1 *}$ (D) Meinolf Wonnemann ${ }^{2}$, Oliver Werz ${ }^{3}$ and Martin D. Lehner ${ }^{1}$
}

\begin{abstract}
Background: The herbal medicinal product Bronchipret ${ }^{\oplus}$ TP film-coated tablets contains a fixed combination of thyme and primula dry extracts (BRO) and has long and successfully been used for the treatment of acute bronchitis. However, the underlying pharmacological mechanisms of action have not been determined so far. We report a tiered approach applying in vivo and in vitro studies to investigate the pharmacodynamic activity and underlying mechanisms of action, and to identify possible active ingredients contributing to the product's pharmacodynamic activity.
\end{abstract}

Results: In an LPS-induced rat model of bronchoalveolitis oral administration of BRO effectively ameliorated the influx of leukocytes into the lung. This was accompanied by reduced levels of leukotriene $(L T) B_{4}$, cysteinyl-LTs (cys $L T$ ), and prostaglandin $(P G) E_{2}$. We also found that $B R O$ potently reduced the production of $\mathrm{LTB}_{4}$ in vitro in rat whole blood stimulated with the $\mathrm{Ca}^{2+}$-ionophore $\mathrm{A} 23187$ whereas the effect on $\mathrm{PGE}_{2}$ was much less pronounced. The transferability of these findings to human cells was assessed by measuring the effects of BRO on A23187stimulated human monocytes and neutrophils. BRO and thyme extract were potent inhibitors of $\mathrm{LTB}_{4}$ and cysLT production. We further investigated the effects of $\mathrm{BRO}$, thyme extract as well as single compounds of thyme extract on enzymatic activity of 5-lipoxygenase (5-LO). 5-LO activity was potently reduced by BRO and thyme extract. Of the single ingredients, thymoquinone and rosmarinic acid showed most potent inhibitory activity against 5-LO, with lower potency for thymol and carvacrol.

Conclusion: BRO attenuates inflammation-induced leukotriene formation in vivo and affects leukotriene biosynthesis in vitro via 5-LO inhibition. This inhibitory activity appears to be primarily related to the thyme extract component. However, none of the single ingredients tested seems to fully account for the activity of thyme extract alone. Rather, the interaction of different compounds seems to be required for its overall inhibitory effect on leukotriene production.

Keywords: Bronchipret, Thyme, Primula, Airway inflammation, Leukotriene, 5-lipoxygenase, Thymol, Carvacrol, Rosmarinic acid, Thymoquinone

\footnotetext{
* Correspondence: jan.seibel@bionorica.de

${ }^{1}$ Bionorica SE, Dept. Preclinical R\&D, Kerschensteinerstr. 11-15, D-92318

Neumarkt, Germany

Full list of author information is available at the end of the article
} 


\section{Background}

Bronchipret $^{\oplus}$ TP film-coated tablets (Bronchipret ${ }^{\oplus} \mathrm{TP}$ ) is an herbal medicinal product containing a fixed combination of dry extracts from thyme herb and primula roots. It has been used as a remedy for cough with excessive mucus during infections/inflammation of the lower respiratory tract for more than 20 years with a currently recommended daily dose of 660 mg.day $^{-1}$ for adult patients [1]. A clinical trial in patients with acute bronchitis and cough performed at this daily dose demonstrated therapeutic efficacy of Bronchipret $^{\oplus}$ TP on symptom relieve and recovery time [2]. The clinical evidence of efficacy led to a recommendation of Bronchipret ${ }^{\oplus}$ TP in the S3 guideline of the German Respiratory Society on the diagnosis and treatment of cough in adults [3].

Acute bronchitis is a predominantly self-limited respiratory disease that in most cases develops in the course of infection with respiratory viruses that trigger an inflammatory reaction in the infected airways leading to an increased production of viscous mucus and consequently cough. These symptoms are the most incriminating ones for the patient [4]. The symptomatic therapy of the inflammatory processes and their normalization therefore represents a key target for pharmacological intervention.

For Bronchipret ${ }^{\oplus}$ syrup, containing a fixed combination of thyme and ivy fluid extracts, anti-inflammatory activity was recently verified and interference with the production and/or release of eicosanoids as mediators has been suggested as a possible mechanism of anti-inflammatory action [5].

Eicosanoids are lipid mediators derived from the arachidonic acid (AA) metabolic pathway and can be subdivided into different groups of which the prostanoids and the leukotrienes are major players involved in regulation of inflammation. The key steps of their production are catalyzed by cyclooxygenases (COX-1 and COX-2) or 5lipoxygenase (5-LO), respectively. The prostaglandin (PG) $\mathrm{PGE}_{2}$ plays important roles in inflammatory processes, e.g. by increasing the permeability of blood vessels, while for the leukotrienes (LT) it is $\mathrm{LTB}_{4}$ that directly drives inflammatory processes. $\mathrm{LTB}_{4}$ acts as a chemoattractant on leukocytes and facilitates their adhesion to blood vessels in inflamed tissue. However, also the cysteinyl leukotrienes (cysLT), potent inducers of bronchoconstriction, contribute to inflammation by increasing vascular permeability and by promoting activation and migration of leukocytes, particularly in the airways $[6,7]$.

For herbal extracts, several mechanisms of interference with the production or activity of eicosanoids have been described including the regulation of enzyme expression [8-10] and enzyme activity [11], but also by influencing the expression of eicosanoid receptors $[8,12]$.

Similarly, several single compounds of herbal origin such as flavonoids, quinones, sesquiterpenes, etc. have been shown to reduce eicosanoid production [13, 14]. Thyme extracts contain multiple components that act against a broad range of biological targets $[15,16]$. Particularly for thymol, carvacrol and thymoquinone anti-inflammatory actions through inhibition of PG and LT biosynthesis by targeting COX-2 [11, 17] and 5-LO activity [18] have been described.

Starting from its demonstrated clinical efficacy, we applied a tiered approach to study the anti-inflammatory activity of the thyme herb/primula root dry extract mixture that is contained in Bronchipret ${ }^{\oplus}$ TP (BRO) initially in vivo in an animal model of pulmonary inflammation followedup by subsequent in vitro experiments on the eicosanoid pathway in leukocytes and in a cell-free system. We thereby aimed at identifying the underlying mechanisms of action and at detecting possible active ingredients contributing to the product's pharmacodynamic activity.

\section{Methods}

Test items

For in vivo and in vitro experiments a mixture of the genuine dry extracts of thyme herb and primula root contained in Bronchipret ${ }^{\oplus} \mathrm{TP}$ without excipients and with a final thyme/primula dry extract ratio of 2.67:1 (BRO) or the single extracts were used. The extracts are standardized to the content of specific marker compounds. The herbal extract mixture and the single extracts were provided by Bionorica SE, Germany.

For the in vivo studies the dry extract mixture was suspended in $0.9 \%$ saline $\left(\mathrm{w} \cdot \mathrm{w}^{-1}\right)$. For the in vitro experiments the mixture was dissolved in $50 \%$ ethanol $\left(\mathrm{v} \cdot \mathrm{v}^{-1}\right)$ to a concentration of $100 \mathrm{mg} \cdot \mathrm{mL}^{-1}$ and homogenized for $5 \mathrm{~min}$ by vortexing followed by $30 \mathrm{~min}$ incubation in an ultrasonic bath at room temperature (RT). The resulting suspension was then centrifuged at $3000 \times \mathrm{g}$ for $10 \mathrm{~min}$ at RT and the corresponding supernatant was filtrated through a disposable syringe filter (PVDF; pore size, $0.22-0.45 \mu \mathrm{m}$; e.g. Millipore, USA) and immediately used for the assays.

For the investigations on 5-LO activity also the pure compounds thymol (Carl Roth/Lactan, Austria), thymol sulfate (Witega Laboratorien, Germany), carvacrol, thymoquinone and rosmarinic acid (all Sigma-Aldrich, USA) were used. These compounds were dissolved in ethanol at $30 \mathrm{mg} \cdot \mathrm{mL}^{-1}$ and immediately used for the assay. For all studies in rat blood or with human blood cells final ethanol concentrations of $0.5 \%$ or $0.025 \%\left(\mathrm{v} \cdot \mathrm{v}^{-1}\right)$ were used, respectively. In the isolated 5-LO enzyme assays final ethanol concentrations were $0.1 \%$ or $0.25 \%\left(\mathrm{v} \cdot \mathrm{v}^{-1}\right)$. The respective concentrations also served as the vehicle controls.

\section{Anti-inflammatory activity assessment in vivo Animal housing}

The animal studies are reported based on the ARRIVE guidelines [19]. Male Wistar rats weighing 160-260 g 
were obtained from Rappolovo (Russia) and kept in polycarbonate cages (type T4A, $\mathrm{S}=2194 \mathrm{~cm}^{2}$ ) with steel wire grid cover (6 animals per cage) throughout the experiment at room conditions of $21 \pm 1{ }^{\circ} \mathrm{C}$ and $61-75 \%$ humidity in a $12 \mathrm{~h}$ light/dark cycle. Access to water and complete pellet diet (Protein 19\%; Aller Petfood, Russia) was provided ad libitum. Experiments were performed according to the recommendations and policies of the National Standard of Russian Federation GOST R53434-2009, under a protocol which had been previously approved by the Ethics Committee of the SaintPetersburg Institute of Pharmacy JSC (Russia). All painful manipulations of the animals were conducted in accordance with regulatory standards (Directive 2010/ 63/EU of the European parliament and of the council of 22 September 2010 on the protection of animals used for scientific purposes).

\section{Induction of bronchoalveolitis and animal treatment}

Bronchoalveolitis was induced as previously described [5]. In brief, 66 animals ( $n=10$ to 16 per group) were randomly divided and allocated to the 5 treatment groups challenged with LPS and one additional naïve group (healthy control) by means of a modified method of block randomization [20]. The animals were acclimatized for 14 days prior to the start of the experiment.

Manipulations were performed in previously anesthetized animals (Zoletil ${ }^{\circ}$ (tiletamine/zolazepam: Virbac, France) at $0.4 \mathrm{mg} \cdot \mathrm{kg}^{-1}$ body weight (b.w.) i.v.) by intratracheal injection of $100 \mu \mathrm{g}$ LPS from Escherichia coli (Sigma-Aldrich, USA) per animal $1 \mathrm{~h}$ prior to the first oral administration of the test compounds. The animals were then treated once daily by oral gavage with either vehicle $\left(0.9 \%\right.$ saline $\left.\left[\mathrm{w} \cdot \mathrm{w}^{-1}\right]\right)$, dexamethasone (DEX, $5 \mathrm{mg} \cdot \mathrm{kg}^{-1}$ b.w.) or BRO (13.6, 68 or $339 \mathrm{mg} \cdot \mathrm{kg}^{-1}$ b.w.) at an administration volume of $10 \mathrm{~mL} \cdot \mathrm{kg}^{-1}$ b.w.. The doses correspond to the $0.2-, 1$ - and 5-fold of the currently recommended human daily dose after allometric conversion to human equivalent doses [21].

\section{Bronchoalveolar lavage fluid collection and analysis}

Animals were sacrificed by terminal anesthesia with Zoletil $^{\circ}$ at $0.7 \mathrm{mg} \cdot \mathrm{kg}^{-1}$ b.w. i.v. at $48 \mathrm{~h}$ post LPS challenge for sampling of bronchoalveolar lavage fluid (BALF) as described previously [5]. In brief, BALF was collected after ligation of the right main bronchus and a catheter was inserted from the trachea into the left lung. Warm saline $\left(37{ }^{\circ} \mathrm{C}\right)$ was repeatedly run through the catheter and the resulting BALF (ca. $200 \mu \mathrm{l}$ ) was passed through a mesh (200 $\mu \mathrm{m}$; Volga Manufactory, Russia) to remove mucus followed by centrifugation $(1500 \times \mathrm{g})$ at $4{ }^{\circ} \mathrm{C}$ for 15 min (centrifuge Z216 MK, Hermle Labortechnik $\mathrm{GmbH}$, Germany).
The pellets were resuspended and total cell counts were measured with a veterinarian hematological analyzer (Abacus Junior Vet, Diatron, Hungary). Supernatants were removed and stored frozen at $-20{ }^{\circ} \mathrm{C}$ until analysis of eicosanoid levels.

Levels of $\mathrm{PGE}_{2}, \mathrm{LTB}_{4}$ and cysLTs in BALF samples were analyzed by ELISA (Cayman Chemical, USA) according to the manufacturer's instructions.

\section{Analysis of prostaglandin and leukotriene production in rat whole blood}

Blood sampling, treatment, stimulation and quantification of eicosanoids

Whole blood was retro-orbitally sampled from 4 male Wistar Han IGS rats (Charles River Laboratories, France) previously anaesthetized with isoflurane into tubes containing heparin, pooled, diluted in RPMI medium (1:1) and then plated in 24-well plates $\left(470 \mu \mathrm{L} \cdot\right.$ wells $\left.^{-1}\right)$. BRO was added in duplicates to reach final concentrations of 1, 3, 10, 30, 100 and $300 \mu \mathrm{g} \cdot \mathrm{mL}^{-1}$ $5 \mathrm{~min}$ prior to addition of A23187 at $15 \mu \mathrm{g} \cdot \mathrm{mL}^{-1}$. The plates were incubated at $37{ }^{\circ} \mathrm{C}$ for $120 \mathrm{~min}$. To stop the reaction, plates were placed on ice for $5 \mathrm{~min}$ and then centrifuged at $300 \times \mathrm{g}$ for $10 \mathrm{~min}$ at $4{ }^{\circ} \mathrm{C}$.

Supernatants were collected, aliquoted and stored at $-80{ }^{\circ} \mathrm{C}$ prior to eicosanoid quantification.

$\mathrm{LTB}_{4}$, cysLTs and $\mathrm{PGE}_{2}$ were quantified using EIA kits (Cayman Chemical, USA) according to the manufacturer's instructions.

\section{Analysis of leukotriene production in human blood cells Human blood cells and cell isolation}

Neutrophils and monocytes were isolated from buffy coats from healthy adult volunteers obtained at the Institute of Transfusion Medicine, University Hospital Jena, Germany. Neutrophils were immediately isolated by dextran sedimentation and centrifugation on Nycoprep cushions (PAA Laboratories, Austria) followed by hypotonic lysis of erythrocytes as previously described [22]. Monocytes were separated from peripheral blood mononuclear cells by adherence to culture flasks as described in [23]. Cells were finally resuspended in PBS pH 7.4 containing $1 \mathrm{mg} \cdot \mathrm{mL}^{-1}$ glucose and $1 \mathrm{mM} \mathrm{CaCl} 2$ (PGC buffer).

\section{Analysis of cytotoxicity in intact human neutrophils and monocytes}

Neutrophil and monocyte viability was analyzed by MTT assay (determination of 3-(4, 5-dimethyl-2-thiazolyl)-2, 5diphenyl-2H-tetrazolium bromide (MTT) reduction to formazan) as described before [24]. Test compounds or vehicle $\left(0.375 \%\right.$ ethanol $\left[\mathrm{v} \cdot \mathrm{v}^{-1}\right]$, final concentration) were added to the cells seeded in 96-well plates and samples 
were incubated for $30 \mathrm{~min}$ at $37^{\circ} \mathrm{C}$; positive control for cell lysis: $1 \%$ triton or $16.6 \%$ ethanol $\left(\mathrm{v} \cdot \mathrm{v}^{-1}\right)$.

\section{$L T B_{4}$ formation in intact human neutrophils}

Neutrophils $\left(5 \times 10^{6}\right.$ cells. $\mathrm{mL}^{-1}$ PGC buffer $)$ were preincubated with the compounds or vehicle $(0.025 \%$ ethanol $\left.\left[\mathrm{v} \cdot \mathrm{v}^{-1}\right]\right)$ for $10 \mathrm{~min}$ at $37{ }^{\circ} \mathrm{C}$ and then stimulated for another $10 \mathrm{~min}$ with ionophore A23187 $(2.5 \mu \mathrm{M})$. The reaction was stopped with $1 \mathrm{~mL}$ of methanol and $30 \mu \mathrm{L} 1 \mathrm{~N}$ $\mathrm{HCl}$ before $500 \mu \mathrm{L}$ PBS and $200 \mathrm{ng} \mathrm{PGB}_{1}$ (internal standard) were added. The samples were subjected to solidphase HPLC extraction on C18-columns (100 mg, UCT, USA) and analyzed by RP-HPLC as described [25]. LTB $_{4}$ quantities were calculated on the basis of $\mathrm{PGB}_{1}$. Amounts of the cysLTs $\mathrm{C}_{4}, \mathrm{D}_{4}$ and $\mathrm{E}_{4}$ (as determined with the enzyme immunoassay kit specified in the following paragraph) were below the detection limit.

\section{CysLT formation in intact human monocytes}

Monocytes $\left(1 \times 10^{6}\right.$ cells. $\mathrm{mL}^{-1}$ in PGC buffer $)$ were incubated for $10 \mathrm{~min}$ at $37^{\circ} \mathrm{C}$ with test compounds or ve-

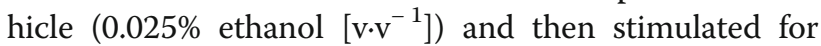
10 min with ionophore A23187 $(2.5 \mu \mathrm{M})$. The reaction was stopped on ice, samples were centrifuged at $500 \times \mathrm{g}$ for $10 \mathrm{~min}$ at $4{ }^{\circ} \mathrm{C}$ and supernatants were analyzed for cysLT levels using an enzyme immunoassay kit which detects $\mathrm{LTC}_{4}, \mathrm{D}_{4}$ and $\mathrm{E}_{4}$ according to the manufacturer's instructions (Sapphire Biosciences, Australia).

\section{Activity of purified 5-LO}

Human recombinant 5-LO was expressed in E. coli BL21 (DE3) cells, transformed with pT3-5LO and purified by using an ATP-agarose column [26]. 5-LO $\left(0.5 \mu \mathrm{g} \cdot \mathrm{mL}^{-1}\right.$ PBS, $\mathrm{pH} 7.4,1 \mathrm{mM}$ EDTA, $1 \mathrm{mM}$ ATP) was preincubated for $10 \mathrm{~min}$ at $4{ }^{\circ} \mathrm{C}$ with test compounds or vehicle $\left(0.25 \%\right.$ ethanol $\left.\left[\mathrm{v} \cdot \mathrm{v}^{-1}\right]\right)$, pre-warmed for $30 \mathrm{~s}$ at $37^{\circ} \mathrm{C}$ and $2 \mathrm{mM} \mathrm{CaCl}_{2}$ and $20 \mu \mathrm{M}$ AA were added. The reaction was stopped after $10 \mathrm{~min}$ at $37^{\circ} \mathrm{C}$ by addition of icecold methanol and $\mathrm{PGB}_{1}$. Formed metabolites (all-trans isomers of $\mathrm{LTB}_{4}$ and $\left.5-\mathrm{H}(\mathrm{P}) \mathrm{ETE}\right)$ were extracted by solid phase extraction on C18-columns and analyzed by HPLC as described above. Inhibition of 5-LO activity by the compounds was calculated as the percentage of basal 5LO product formation.

\section{Statistics}

In vivo study data are presented as individual data and means in the form of scatter plots. Statistical data evaluation versus LPS/vehicle control was performed by oneway analysis of variance (ANOVA) followed by Dunnett's Multiple Comparison Test of log-transformed data.

For in vitro experiments results are expressed as arithmetic means \pm SD of duplicates in one experiment (rat whole blood) or as arithmetic means \pm SEM of at least two independent experiments, each collecting single data points (human blood cells and isolated 5-LO). $\mathrm{IC}_{50}$ values were calculated by non-linear regression. Statistical analyses and approximations were done with GraphPad Prism 7 software (GraphPad Software Inc., USA). A $p$ value $<0.05$ was considered statistically significant.

\section{Results}

Effects of BRO on markers of inflammation in an animal model of pulmonary inflammation

The anti-inflammatory potential of BRO was investigated in a rat model of LPS-induced pulmonary inflammation following oral administration of BRO at three dose levels (14, 68 and $339 \mathrm{mg} \cdot \mathrm{kg}^{-1}$ ) according to the 0.2-, 1- and 5fold equivalent of the recommended human daily dose.

Intratracheal administration of LPS (100 $\mu \mathrm{g}$ per rat) led to the development of a strong inflammatory response in the lungs characterized by an increase in total cell numbers (Fig. 1a) consisting mainly of granulocytes (77 $\pm 8 \%$ in LPS vehicle group vs. $12 \pm 3 \%$ in healthy animals) and the release of the eicosanoids $\mathrm{PGE}_{2}$ (Fig. 1b), $\mathrm{LTB}_{4}$ (Fig. 1c), and cysLT (Fig. 1d) as measured in BALF $48 \mathrm{~h}$ post stimulation.

Treatment with BRO led to a dose-dependent attenuation of the inflammatory changes with a similar magnitude as the reference control DEX (5 mg. $\mathrm{kg}^{-1}$ b.w.). Particularly, total cells and $\mathrm{LTB}_{4}$ content in BALF returned close to basal levels upon administration of BRO at the mid and high dose levels (68 and $339 \mathrm{mg} \cdot \mathrm{kg}^{-1}$ ).

\section{Effects of $\mathrm{BRO}$ on $\mathrm{LTB}_{4}$ and $\mathrm{PGE}_{2}$ release from rat whole blood}

In order to assess whether BRO exerts a direct effect on eicosanoid release from leukocytes we investigated the effect of BRO on eicosanoid production in rat whole blood stimulated with the $\mathrm{Ca}^{2+}$-ionophore A23187, a commonly used agent to induce 5-LO product formation. Stimulation of blood increased the release of $\mathrm{LTB}_{4}$ from $0.178 \pm 0.026$ to $9.8 \pm 3.0 \mathrm{ng} \cdot \mathrm{mL}^{-1}$ and of $\mathrm{PGE}_{2}$ from $1.8 \pm 0.3$ to $7.5 \pm 0.5 \mathrm{ng} \cdot \mathrm{mL}^{-1}$.

Release of both $\mathrm{LTB}_{4}$ and $\mathrm{PGE}_{2}$ was concentrationdependently inhibited by $\mathrm{BRO}$ in a concentration range of 0.3 to $300 \mu \mathrm{g} \cdot \mathrm{mL}^{-1}$ with $\mathrm{IC}_{50}$ values of 8.6 and $70.0 \mu \mathrm{g} \cdot \mathrm{mL}^{-1}$ for $\mathrm{LTB}_{4}$ and $\mathrm{PGE}_{2}$, respectively (Fig. 2).

Due to the rather weak inhibitory potency on $\mathrm{PGE}_{2}$ and in vitro data that show a lack of inhibition by $\mathrm{BRO}$ on both isolated ovine COX-1 and human recombinant COX-2 enzyme activity at concentrations up to $300 \mu \mathrm{g} \cdot \mathrm{mL}^{-1}$ (unpublished data) we subsequently focused our investigations on the effects on the leukotriene branch of the AA metabolic pathway. 

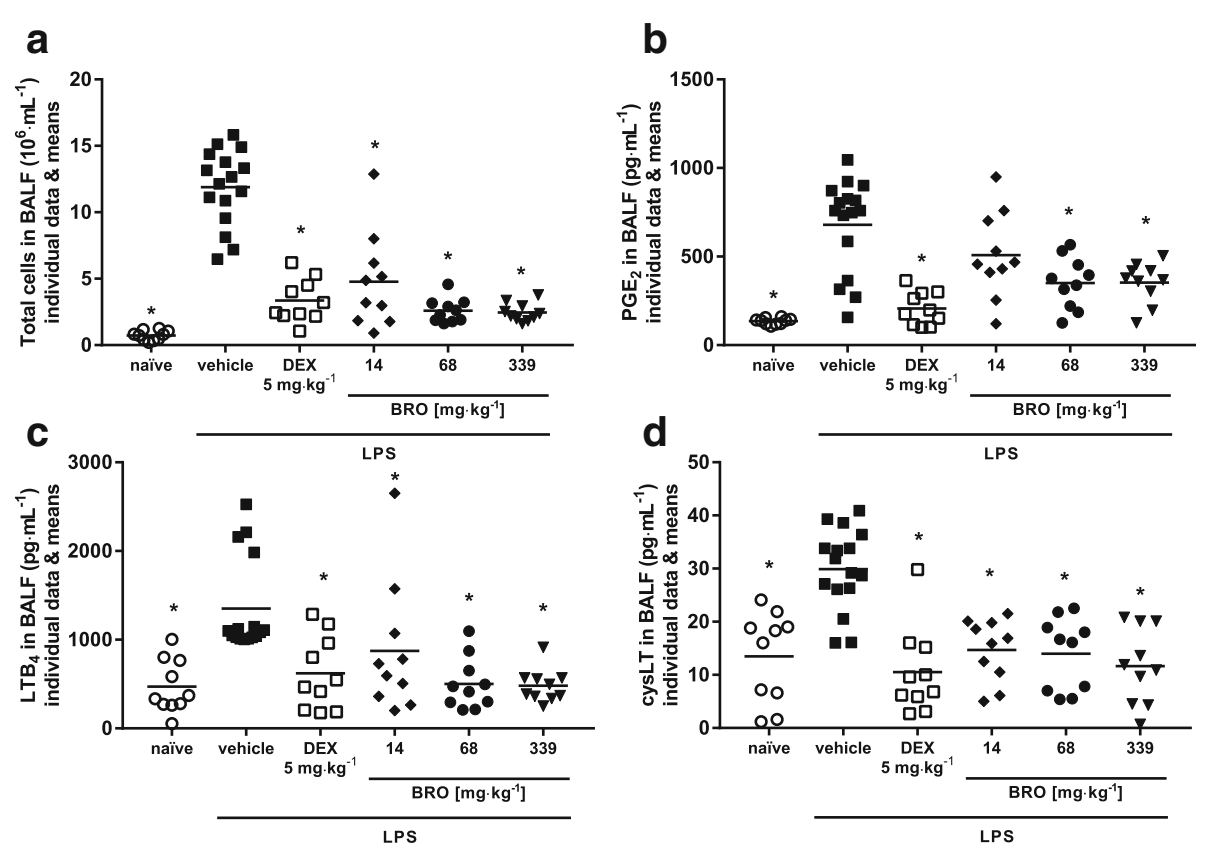

Fig. 1 Analysis of the effects of BRO on inflammatory parameters in BALF. Oral treatment with BRO significantly reduced (a) total cells, (b) PGE (c) $L_{T B}$ and (d) cysLT levels in BALF of rats challenged intratracheally with LPS. Data are given as individual values and their means. ${ }^{*}$ statistically significant versus LPS/vehicle; $p<0.05$; ANOVA of log-transformed data + Dunnett's test

\section{Effects of BRO on cysLT and $\mathrm{LTB}_{4}$ release from human blood cells}

In order to evaluate if the results obtained in the rat are transferrable to humans we evaluated the release of $\mathrm{LTB}_{4}$ and cysLTs from A23187-stimulated human neutrophils and monocytes, respectively. To furthermore narrow down the active compounds in BRO we also included the single extracts of thyme herb and primula

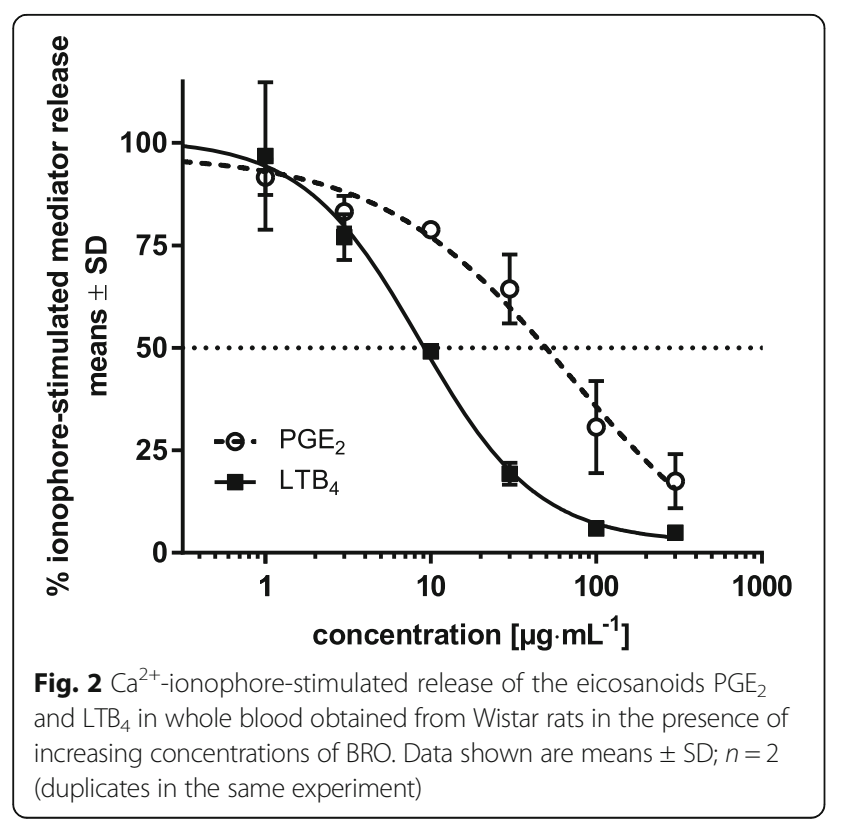

root in these assays. Cytotoxicity testing allowed for a concentration range of 0.4 to $100 \mu \mathrm{g} \cdot \mathrm{mL}^{-1}$ for all test items to be used in the assays (data not shown).

In analogy to rat whole blood $\mathrm{BRO}$ concentrationdependently diminished the formation of $\mathrm{LTB}_{4}$ in human neutrophils (Fig. 3a) reaching complete inhibition at $100 \mu \mathrm{g} \cdot \mathrm{mL}^{-1}$ with an $\mathrm{IC}_{50}$ value of $40.6 \mu \mathrm{g} \cdot \mathrm{mL}^{-1}$. Thyme and primula extract displayed similar activity with $\mathrm{IC}_{50}$ values of 27.8 and $34.3 \mu \mathrm{g} \cdot \mathrm{mL}^{-1}$, respectively.

Moreover, BRO and thyme extract both potently inhibited cysLT release from human monocytes (Fig. 3b) with $\mathrm{IC}_{50}$ values of 10.6 and $12.2 \mu \mathrm{g} \cdot \mathrm{mL}^{-1}$, respectively, while the primula extract demonstrated a weaker effect on cysLT release $\left(\mathrm{IC}_{50}\right.$ of $\left.30.4 \mu \mathrm{g} \cdot \mathrm{mL}^{-1}\right)$.

Further experimentation therefore focused on the thyme herb component of BRO.

Inhibition of 5-LO enzyme activity by BRO, thyme extract and single compounds

5-LO is the enzyme catalyzing the first key steps in leukotriene biosynthesis. In order to assess whether the observed cellular effects of BRO and thyme extract were due to a direct interference with 5-LO activity we investigated the effects of BRO and thyme extract on purified human recombinant 5-LO in a cell-free system. Indeed, both $\mathrm{BRO}$ and thyme extract inhibited 5-LO activity with $\mathrm{IC}_{50}$ values of 3.4 and $18.7 \mu \mathrm{g} \cdot \mathrm{mL}^{-1}$, respectively (Fig. 4a).

Finally, we tried to identify single components that are potentially responsible for the activity of thyme extract. 

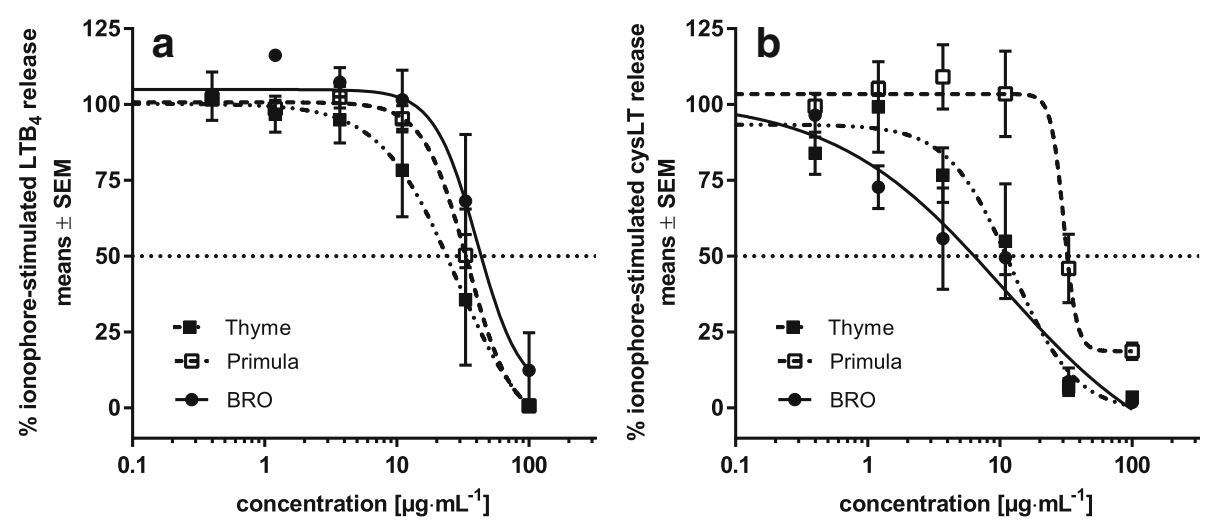

Fig. $3 \mathrm{Ca}^{2+}$-ionophore-stimulated release of the eicosanoids (a) $\mathrm{LTB}_{4}$ from human neutrophils and (b) cys $L T$ from human monocytes in the presence of increasing concentrations of $\mathrm{BRO}$ or of the single extracts from thyme and primula. Data shown are means \pm SEM; $n=3$ (individual experiments)

Thymoquinone, rosmarinic acid, thymol, carvacrol and the phase II metabolite thymol sulfate all inhibited 5-LO activity with $\mathrm{IC}_{50}$ values of $1.1,7.7,16.0,24.5$ and $89.4 \mu \mathrm{g} \cdot \mathrm{mL}^{-1}$, respectively (Fig. $4 \mathrm{~b}$ ). Mean basal 5 -LO product formation (100\% control) over all performed experiments was $643 \pm 325 \mu \mathrm{g} \cdot \mu \mathrm{L}^{-1}$ (mean $\pm \mathrm{SD}$ ).

\section{Discussion}

Starting from the clinically proven efficacy of Bronchipret $^{\circ}$ TP in patients suffering from acute bronchitis [2] our aim was to elucidate the product's mechanisms of action and to identify single ingredients contributing to its pharmacodynamic activity.

Unfortunately, replication of the condition of virally induced acute and self-limiting bronchitis in animal models is quite challenging due to differences in susceptibility to viral pathogens as compared to humans. We therefore investigated the effects of orally administered BRO in a more mechanistic animal model of pulmonary inflammation induced by intratracheally administered LPS. This model has been previously reported to be a suitable system to study self-limiting bronchial inflammation in animals with similar features to acute bronchitis, although it lacks the viral etiology typical for acute bronchitis in humans [27]. LPS induces strong non-specific immune responses in the lung, leading to an infiltration of leukocytes and pulmonary edema. This response is mediated by a mixture of various leukocytes (including neutrophilic granulocytes and monocytes). Based on the results of an earlier study with Bronchipret $^{\circ}$ syrup [5] we analyzed selected inflammatory parameters at $48 \mathrm{~h}$ post LPS challenge after two treatments with BRO at doses according to the 0.2-, 1- and 5-fold equivalent of the recommended daily dose in humans.

Treatment of the animals with BRO had a clearly positive effect on the extent of inflammation as was shown by the significant reduction in the influx of leukocytes into the lung (Fig. 1a). These results clearly indicate anti-inflammatory efficacy of orally administered BRO at clinically relevant dose equivalents in vivo. In addition, BRO therapy attenuated the increase in the proinflammatory eicosanoids $\mathrm{PGE}_{2}, \quad \mathrm{LTB}_{4}$ and cysLT (Fig. 1b-d), suggesting that direct or indirect interference with the AA metabolic pathway could be a potential
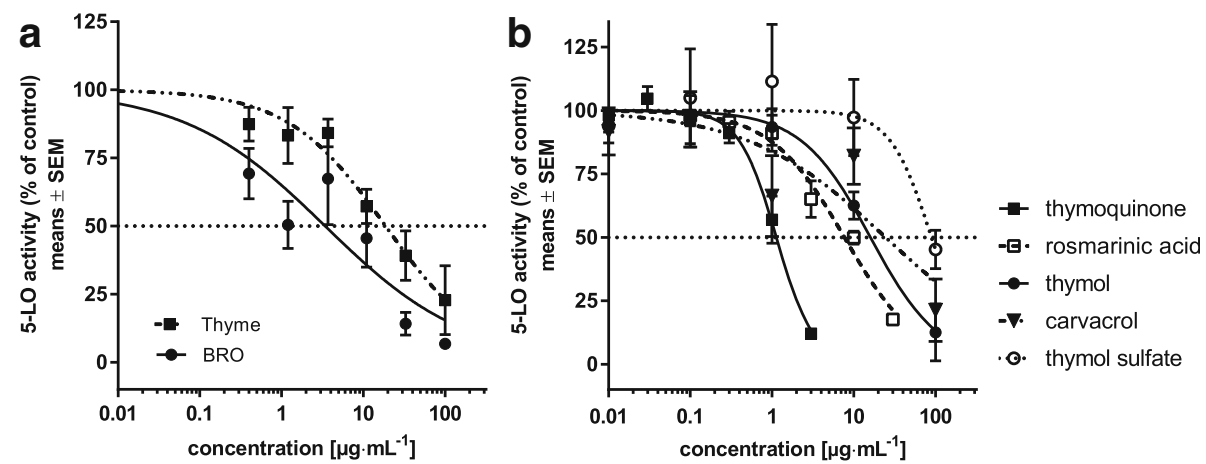

Fig. 4 Inhibition of purified human recombinant 5-LO enzyme activity by (a) BRO and thyme extract and (b) the single compounds thymol, thymol sulfate, carvacrol, thymoquinone and rosmarinic acid. Data shown are means \pm SEM; $n=3-4$ (individual experiments). Basal 5-LO product formation (100\% control) was $643 \pm 325.3 \mu \mathrm{g} \cdot \mathrm{LL}^{-1}$ (mean $\left.\pm \mathrm{SD}\right)$ 
mode of action of BRO. To further characterize the inhibitory effect of BRO on the arachidonic acid pathway, we studied the effect on eicosanoid production in an in vitro model of stimulated rat blood. Ionophore-induced $\mathrm{LTB}_{4}$ release was potently inhibited by BRO addition $\left(\mathrm{IC}_{50}: 8.6 \mu \mathrm{g} \cdot \mathrm{mL}^{-1}\right)$ whereas the effect on $\mathrm{PGE}_{2}$ release was considerably less potent $\left(\mathrm{IC}_{50}: 70.0 \mu \mathrm{g} \cdot \mathrm{mL}^{-1}\right)$. This finding demonstrates that $\mathrm{BRO}$ directly affects eicosanoid release from leukocytes under in vitro conditions. Since the effect on $\mathrm{LTB}_{4}$ release was considerably more potent than the inhibition of $\mathrm{PGE}_{2}$ production and in vitro tests had revealed that $\mathrm{BRO}$ has no effect on COX2 enzyme activity (unpublished data), we subsequently focused our efforts on characterizing the effect of BRO on the leukotriene branch of the AA metabolic pathway. Our studies in human leukocytes confirmed that the inhibitory activity of BRO on leukotriene release observed in the rat also applies to cells of human origin (Fig. 3). By testing BRO and its single extract components from thyme herb and primula root we further expected to gain information which of the ingredients of $\mathrm{BRO}$ is mainly responsible for this pharmacodynamic activity. The strongest inhibitory effect (lowest $\mathrm{IC}_{50}$ values) on leukotriene release was observed for both BRO and thyme extract (Fig. 3) which prompted us to focus on the thyme component in subsequent analyses. Moreover, cysLT (Fig. 3b) was more susceptible to inhibition than $\mathrm{LTB}_{4}$ (Fig. 3a).

The fact that both cysLT and $\mathrm{LTB}_{4}$ release were affected by BRO suggests that an interference with 5-LO, the key enzyme of leukotriene biosynthesis, might be responsible. Indeed, both BRO and thyme extract caused marked inhibition of 5-LO activity (Fig. 4a) corroborating the hypothesis that 5-LO activity is a pharmacological target of BRO. These results also confirm previously published data for Bronchipret ${ }^{\circ}$ syrup [5].

For several individual chemical constituents from thyme extract different anti-inflammatory activities have been described. Of these, the terpenol phenols thymol and carvacrol have been most intensively studied with respect to their anti-inflammatory activity [28-30]. In addition, the tannin rosmarinic acid, has been described to possess anti-inflammatory activity and also to intervene with eicosanoid production [31]. In an attempt to identify the major active individual constituents in our thyme herb extract, we therefore assessed the inhibitory potencies of thymol, carvacrol and rosmarinic acid in the 5-LO assay. We also included the phase I and phase II metabolites of thymol, i.e. thymoquinone and thymol sulfate, respectively, to extend the relevance of our results to the in vivo situation where rapid metabolism of thymol has been demonstrated [32]. The phase-I metabolite thymoquinone [33], which is also an ingredient of thyme, has been reported to be a potent inhibitor of 5-
LO activity and hence leukotriene biosynthesis [18]. Although all single components displayed some inhibitory activity on 5 - $\mathrm{LO}$ the $\mathrm{IC}_{50}$ values were in a similar range as the potency of the thyme herb extract. Given the low relative amount of $<2 \%$ (data not shown) of the individual components in the thyme extract, probably none of them could solely account for the full activity of thyme extract. It rather appears that 5 - $\mathrm{LO}$ inhibition by thyme extract and BRO represents the sum of individual inhibitory activities of several active ingredients. Concerning thymol metabolites, the concentration of thymol sulfate required for relevant 5-LO inhibition is not expected to be reached after oral administration of the clinical dose (Kohlert et al. described a $\mathrm{C}_{\max }$ of $93 \mathrm{ng} \cdot \mathrm{mL}^{-1}$ for thymol sulfate in human plasma following the intake of one Bronchipret $^{\circ} \mathrm{TP}$ tablet [32]). Hence, a relevant contribution of thymol sulfate to the observed reduction of leukotriene levels in our rat model also seems unlikely. Thymoquinone displayed the highest potency in our assay. Unfortunately, the lack of bioanalytical data following oral BRO administration prevents any meaningful evaluation of the in vivo relevance of thymoquinone for leukotriene inhibitory effect of BRO. Although the results of these experiments suggest that it is mainly the thyme component contributing to BRO's antiinflammatory activity, it needs the combination with primula that is necessary to explain the full pharmacodynamic activity range of BRO. For example, in the guinea pig model of citric acid-induced cough we could show that BRO exerts potent cough-soothing activity [34] and that this is predominantly attributed to its primula extract content.

Our findings complement previous results from Fachini-Queriroz et al. [35] who studied the beneficial effects of Thymus vulgaris essential oil and its terpene components thymol and carvacrol using in vivo (carrageenan-induced pleurisy in rats) and in vitro (chemotaxis of leukocytes isolated from rat pleural cavity) models of inflammatory edema.

Therefore, it seems obvious to consider inhibition of 5$\mathrm{LO}$ as one of the mechanisms of action underlying BRO's anti-inflammatory effects observed in vivo. However, definitive proof for in vivo 5-LO inhibition is still missing and the observed reduction in leukotriene levels in our rat model could also be secondary to a decrease in inflammatory cell influx mediated by other unrelated mechanisms.

Future studies should yield more detailed information on the pharmacokinetics of BRO components to identify sufficiently bioavailable substances that correlate with the pharmacodynamic effects observed in the human organism. In addition, studies assessing the effect on other inflammatory mediator and cytokine pathways beyond the eicosanoids are warranted to fully characterize the pharmacological activity profile of BRO. 


\section{Conclusion}

Bronchipret $^{\oplus} \mathrm{TP}$, an herbal medicinal product that has been successfully used for the treatment of acute bronchitis, exhibits potent anti-inflammatory activity in the animal model of LPS-induced pulmonary inflammation along with inhibition of eicosanoid production. In vitro studies conducted with stimulated rat and human blood cells demonstrated that the thyme/primula extract mixture contained in Bronchipret ${ }^{\oplus} \mathrm{TP}$ preferentially inhibited leukotriene release and that 5 -LO might be the responsible pharmacological target. The inhibitory activity seemed to reside primarily in the thyme extract component, where several active individual chemical constituents were identified that possibly contribute to its 5-LO inhibitory activity. Our findings provide a good starting point to further elucidate PK/PD relations that complement our understanding of the pharmacological mechanisms of the thyme/primula extract mixture in Bronchipret ${ }^{\oplus} \mathrm{TP}$.

\section{Abbreviations}

5-LO: 5-lipoxygenase; AA: arachidonic acid; BALF: bronchoalveolar lavage fluid; BRO: mixture of thyme herb and primula root dry extracts as contained in Bronchipret ${ }^{\oplus}$ TP film-coated tablets; COX: cyclooxygenase;

DEX: dexamethasone; LT: leukotriene; PG: prostaglandin

\begin{abstract}
Acknowledgements
We thank the following persons for their technical contributions: Dr. Kirill Kryshen and co-workers at the Institute of Experimental Pharmacology in St. Petersburg, Russia (in vivo experimental work) as well as Dr. Vincent Baillif and co-workers at Ambiotis SAS in Toulouse, France (leukotriene analyses in rat blood). We furthermore thank Dr. Nina Werthmöller for organization of the rat blood assays.
\end{abstract}

\section{Authors' contributions}

JS made substantial contributions to conception and interpretation of data and has been involved in drafting the manuscript. OW made substantial contributions to acquisition of data and has been involved in critical revision of the manuscript. MW has made substantial contributions to the conception and interpretation of data and critically revised the manuscript. MDL supervised the study, made substantial contributions to conception and interpretation of data and has been involved in drafting the manuscript. All authors read and approved the final manuscript.

\section{Ethics approval and consent to participate}

Experiments were performed according to the recommendations and policies of the National Standard of Russian Federation GOST R-53434-2009, under a protocol which had been previously approved by the Ethics Committee of the Saint-Petersburg Institute of Pharmacy JSC (Russia). All painful manipulations of the animals were conducted in accordance with regulatory standards (Directive 2010/63/EU of the European parliament and of the council of 22 September 2010 on the protection of animals used for scientific purposes)

\section{Competing interests}

Jan Seibel, Meinolf Wonnemann and Martin D. Lehner are employees of Bionorica SE, Germany. Oliver Werz received funding from Bionorica SE, Germany. The authors declare that they have no further competing interests.

\section{Author details}

${ }^{1}$ Bionorica SE, Dept. Preclinical R\&D, Kerschensteinerstr. 11-15, D-92318 Neumarkt, Germany. ${ }^{2}$ Bionorica SE, Dept. Clinical Research International, Kerschensteinerstr. 11-15, D-92318 Neumarkt, Germany. ${ }^{3}$ Chair of Pharmaceutical/Medicinal Chemistry, Friedrich-Schiller-University, D-07743 Jena, Germany.
Received: 17 October 2017 Accepted: 8 January 2018

Published online: 20 February 2018

\section{References}

1. Bionorica SE, Neumarkt i.d.Opf..Summary of Product Characteristics: Bronchipret ${ }^{\oplus}$ TP. Sep 2014, Registration No. 6977077.00 .00 (cited 12-Jan2018). URL: https://www.gelbe-liste.de/produkte/Bronchipret-TP_114944/ fachinformation

2. Kemmerich B. Evaluation of efficacy and tolerability of a fixed combination of dry extracts of thyme herb and primrose root in adults suffering from acute bronchitis with productive cough. A prospective, double-blind, placebo-controlled multicentre clinical trial. Arzneimittelforschung. 2007; 57(9):607-15.

3. Kardos P, Berck H, Fuchs KH, Gillissen A, Klimek L, Morr H, et al. Guidelines of the German respiratory society for diagnosis and treatment of adults suffering from acute or chronic cough. Pneumologie. 2010;64(11):701-11.

4. Verheij TJ, Kaptein AA, Mulder JD. Acute bronchitis: aetiology, symptoms and treatment. Fam Pract. 1989;6(1):66-9.

5. Seibel J, Pergola C, Werz O, Kryshen K, Wosikowski K, Lehner MD, et al. Bronchipret $^{\oplus}$ syrup containing thyme and ivy extracts suppresses bronchoalveolar inflammation and goblet cell hyperplasia in experimental bronchoalveolitis. Phytomedicine : Int. J. Phycol. Pharmacol. 2015;22(13):1172-7.

6. Meirer K, Steinhilber D, Proschak E. Inhibitors of the arachidonic acid cascade: interfering with multiple pathways. Basic Clin. Pharmacol. Toxicol. 2014;114(1):83-91.

7. Xue L, Barrow A, Fleming VM, Hunter MG, Ogg G, Klenerman P, et al. Leukotriene E4 activates human Th2 cells for exaggerated proinflammatory cytokine production in response to prostaglandin D2. J Immunol. 2012; 188(2):694-702.

8. Park JW, Kwon OK, Yuniato P, Marwoto B, Lee J, Oh SR, et al. Amelioration of an LPS-induced inflammatory response using a methanolic extract of Lagerstroemia Ovalifolia to suppress the activation of NF-kappaB in RAW264.7 macrophages. Int J Mol Med. 2016;38(2):482-90.

9. Seibel J, Molzberger AF, Hertrampf T, Laudenbach-Leschowski U, Diel P. Oral treatment with genistein reduces the expression of molecular and biochemical markers of inflammation in a rat model of chronic TNBSinduced colitis. Eur J Nutr. 2009;48(4):213-20.

10. Song $H_{\text {, Lee }}$ YJ. Inhibition of hypoxia-induced cyclooxygenase-2 by Korean red ginseng is dependent on peroxisome proliferator-activated receptor gamma. J. Ginseng Res. 2017;41(3):240-6.

11. Landa P, Kokoska L, Pribylova M, Vanek T, Marsik P. In vitro antiinflammatory activity of carvacrol: inhibitory effect on COX-2 catalyzed prostaglandin E(2) biosynthesis. Arch Pharm Res. 2009;32(1):75-8.

12. Yuan $Y$, Yang $B$, Ye Z, Zhang $M$, Yang $X$, Xin $C$, et al. Sceptridium Ternatum extract exerts antiasthmatic effects by regulating Th1/Th2 balance and the expression levels of leukotriene receptors in a mouse asthma model. J Ethnopharmacol. 2013;149(3):701-6.

13. Hanakova Z, Hosek J, Kutil Z, Temml V, Landa P, Vanek T, et al. Antiinflammatory activity of natural Geranylated Flavonoids: Cyclooxygenase and Lipoxygenase inhibitory properties and proteomic analysis. J Nat Prod. 2017;80(4):999-1006.

14. Werz O. Inhibition of 5-lipoxygenase product synthesis by natural compounds of plant origin. Planta Med. 2007;73(13):1331-57.

15. Begrow F, Engelbertz J, Feistel B, Lehnfeld R, Bauer K, Verspohl EJ. Impact of thymol in thyme extracts on their antispasmodic action and ciliary clearance. Planta Med. 2010;76(4):311-8.

16. Wienkotter N, Begrow F, Kinzinger U, Schierstedt D, Verspohl EJ. The effect of thyme extract on beta2-receptors and mucociliary clearance. Planta Med. 2007;73(7):629-35

17. Marsik P, Kokoska L, Landa P, Nepovim A, Soudek P, Vanek T. In vitro inhibitory effects of thymol and quinones of Nigella Sativa seeds on cyclooxygenase-1- and -2-catalyzed prostaglandin E2 biosyntheses. Planta Med. 2005;71(8):739-42.

18. Landa P, Kutil Z, Temml V, Malik J, Kokoska L, Widowitz U, et al. Inhibition of in vitro leukotriene B4 biosynthesis in human neutrophil granulocytes and docking studies of natural quinones. Nat Prod Commun. 2013;8(1):105-8.

19. Kilkenny C, Browne WJ, Cuthill IC, Emerson M, Altman DG. Improving bioscience research reporting: the ARRIVE guidelines for reporting animal research. PLoS Biol. 2010;8(6):e1000412. 
20. Altman DG, Bland JM. How to randomise. BMJ Clinical research ed. 1999; 319(7211):703-4.

21. U.S. Food and Drug Administration. Guidance for Industry. Estimating the Maximum Safe Starting Dose in Initial Clinical Trials for Therapeutics in Adult Healthy Volunteers. Food and Drug Administration, Center for Drug Evaluation and Research (CDER). 2005.

22. Pergola C, Dodt G, Rossi A, Neunhoeffer E, Lawrenz B, Northoff H, et al. ERKmediated regulation of leukotriene biosynthesis by androgens: a molecular basis for gender differences in inflammation and asthma. Proc Natl Acad Sci U S A. 2008;105(50):19881-6.

23. Pergola C, Rogge A, Dodt G, Northoff H, Weinigel C, Barz D, et al. Testosterone suppresses phospholipase $D$, causing sex differences in leukotriene biosynthesis in human monocytes. FASEB journal : Off. Pub Fed Am Soc Exp. Biol. 2011;25(10):3377-87.

24. Koeberle A, Zettl H, Greiner C, Wurglics M, Schubert-Zsilavecz M, Werz O. Pirinixic acid derivatives as novel dual inhibitors of microsomal prostaglandin E2 synthase-1 and 5-lipoxygenase. J Med Chem. 2008; 51(24):8068-76

25. Werz O, Burkert E, Samuelsson B, Radmark O, Steinhilber D. Activation of 5lipoxygenase by cell stress is calcium independent in human polymorphonuclear leukocytes. Blood. 2002;99(3):1044-52.

26. Fischer L, Szellas D, Radmark O, Steinhilber D, Werz O. Phosphorylation- and stimulus-dependent inhibition of cellular 5-lipoxygenase activity by nonredox-type inhibitors. FASEB journal : Off. Pub Fed Am Soc Exp. Biol. 2003;17(8):949-51.

27. Harris JF, Aden J, Lyons CR, Tesfaigzi Y. Resolution of LPS-induced airway inflammation and goblet cell hyperplasia is independent of IL-18. Respir Res. 2007:8:24.

28. Games E, Guerreiro M, Santana FR, Pinheiro NM, de Oliveira EA, Lopes FD, et al. Structurally related Monoterpenes p-cymene, Carvacrol and Thymol isolated from essential oil from leaves of Lippia sidoides Cham. (Verbenaceae) protect mice against Elastase-induced emphysema. Molecules. 2016:21(10)

29. Gholijani N, Gharagozloo M, Kalantar F, Ramezani A, Amirghofran Z. Modulation of cytokine production and transcription factors activities in human Jurkat T cells by Thymol and Carvacrol. Advanced pharmaceutical bulletin. 2015:5(Suppl 1):653-60.

30. Khosravi AR, Erle DJ. Chitin-induced airway epithelial cell innate immune responses are inhibited by Carvacrol/Thymol. PLoS One. 2016; 11(7):e0159459.

31. Swarup V, Ghosh J, Ghosh S, Saxena A, Basu A. Antiviral and antiinflammatory effects of rosmarinic acid in an experimental murine model of Japanese encephalitis. Antimicrob Agents Chemother. 2007;51(9):3367-70

32. Kohlert C, Schindler G, Marz RW, Abel G, Brinkhaus B, Derendorf H, et al. Systemic availability and pharmacokinetics of thymol in humans. J Clin Pharmacol. 2002:42(7):731-7.

33. Thalhamer B, Buchberger W, Waser M. Identification of thymol phase I metabolites in human urine by headspace sorptive extraction combined with thermal desorption and gas chromatography mass spectrometry. J Pharm Biomed Anal. 2011:56(1):64-9.

34. Seibel J, Pergola C, Werz O, Wosikowski K, Haunschild J. A combination of thyme and primula dry extracts possesses antitussive activity and inhibits leukotriene formation. Eur Respir J. 2013;42(Suppl 57)

35. Fachini-Queiroz FC, Kummer R, Estevao-Silva CF, Carvalho MD, Cunha JM, Grespan R, et al. Effects of Thymol and Carvacrol, constituents of Thymus Vulgaris $L$. essential oil, on the inflammatory response. Evid. Based Complement. Alternat. Med. 2012;2012:657026.

\section{Submit your manuscript to a SpringerOpen ${ }^{\circ}$ journal and benefit from:}

- Convenient online submission

- Rigorous peer review

- Open access: articles freely available online

- High visibility within the field

- Retaining the copyright to your article

Submit your next manuscript at $\boldsymbol{\nabla}$ springeropen.com 